\title{
O PAPEL DO PATRIMÔNIO HISTÓRICO NA CONSTRUÇÃO DO LUGAR'.
}

\author{
Silmara Dias Feiber ${ }^{2}$
}

A presente investigação procura compreender as funções do "Lugar", para isto parte em busca de elementos que traduzam a sua formação. Significa, portanto ir atrás da identificação do Patrimônio Histórico de uma determinada comunidade o qual colabora, por meio do processo de significação, na formação da legibilidade do Lugar. Para tanto, toma-se por objeto de estudo, a Igreja Nossa Senhora de Fátima localizada originalmente no Distrito São João D'Oeste - Município de Cascavel/Pr. O trabalho organiza-se em três etapas distintas. Inicia-se pela verificação, dentro do âmbito da Geografia, em que contexto o "Lugar" passa de conceito para categoria de análise do saber geográfico. Esta categoria será investigada na interface entre Geografia Social e Cultural, pois se acredita que a relação indivíduo/patrimônio nasce de um processo cultural numa determinada sociedade e em dado momento histórico. A segunda etapa apóia-se na ciência da Semiótica, Filosofia, Sociologia e Psicologia Social para que se possa verificar como ocorre o processo de significação. As teorias vindas destas ciências trazem o conceito de Significação, ou seja, é neste momento em que se buscará avaliar a mudança de valores entre um elemento do cotidiano - Igreja - que passa a ser um elemento de identidade local. Na terceira etapa pesquisa-se o estudo de caso, a Igreja Nossa Senhora de Fátima de Cascavel. Espera-se, com este exemplo concreto, compreender melhor a relação entre indivíduo, sociedade, lugar e seus respectivos elementos formadores, verificando assim o papel do Patrimônio Histórico na construção do Lugar de Cascavel/Pr.

PALAVRAS-CHAVE: Iugar; patrimônio histórico; significação; Cascavel-Pr.

\footnotetext{
${ }^{1}$ Orientador: Prof. Dr. Wolf Dietrich Sahr

${ }^{2}$ Mestranda em Geografia (UFPR) - e-mail: sdfeiber@pop.com.br
} 